\title{
Análisis de los materiales de información a la ciudadanía de la campaña del Ministerio de Sanidad Este virus lo paramos unidos publicados entre marzo y mayo de 2020
}

\section{Analysis of citizen information materials from the Ministry of Health's Campaign We stop this virus together published from March to May 2020}

\author{
Elisa Huertas Ciórraga ${ }^{a}$ \\ a Departamento de Comunicación, Universidad Carlos III de Madrid, España
}

\section{Resumen}

Introducción: La comunicación sanitaria puede proteger la salud y la calidad de vida individuales. Durante las crisis sanitarias deben adaptarse los mensajes a la población. Objetivo: Analizar los materiales de la campaña del Ministerio de Sanidad Este virus lo paramos unidos. Metodología: Se recopilaron todos los materiales de dicha campaña destinados a población general publicados en los meses de marzo, abril y mayo en la Web del Ministerio de Sanidad. Posteriormente se establecieron dos análisis: la forma de presentar el mensaje y el tipo de información que contenían. Resultados: La mayoría de los mensajes son correctos, rigurosos, claros y de fácil comprensión según criterios como la longitud del mensaje. También presentan fecha de publicación y apoyo visual. Sin embargo, deberían incluirse más fuentes de información. Conclusiones: El análisis ha sido positivo en cuanto al contenido, la exactitud, la claridad y la longitud de los mensajes, y en cuanto a la presencia de fechas de publicación y apoyo visual. El tipo de contenido mayoritario es la prevención de contagios.

Palabras clave: campaña; coronavirus; SARS-CoV-2; Covid-19; comunicación; Ministerio de Sanidad.

\begin{abstract}
Introduction: Health communication may protect an individual's health and quality of life. During healthcare crisis, messages must be adapted to the population. Objective: To analyse the materials of the Ministry of Health's campaign We can stop this virus together. Methodology: The materials aimed at the general public that were published in March, April and May on the Ministry of Health's website were compiled. Subsequently, they were assessed following two criteria: how they presented the message and the type of information they contained. Results: The majority of the messages are accurate, rigorous, clear and easily understandable according to criteria such as message length. They also show publication dates and visual support. However, more sources of information should be included. Conclusion: The analysis has been positive regarding content, accuracy, clarity and length of messages, presence of publication dates and visual support. Communication is focused on prevention.
\end{abstract}

Key words: campaign; coronavirus; SARS-CoV-2; Covid-19; communication; Ministry of Health. 


\section{Introducción}

a comunicación de la salud estudia estrategias para informar e influenciar decisiones individuales y comunitarias que mejoren la salud, entendiendo ésta como un estado de completo bienestar físico, mental y social, y no solamente la ausencia de afecciones o enfermedades. Este tipo de comunicación se destina tanto a la prevención de enfermedades como a la promoción de la salud (Organizaición Mundial de la Salud [OMS], 2016). Además, puede influir en la agenda pública, abogar por políticas y programas, promover cambios positivos en ambientes socioeconómicos y físicos, mejorar la sanidad pública e incentivar normas sociales que beneficien la salud y la calidad de vida. Las instituciones sanitarias utilizan recursos tecnológicos como Internet para captar determinadas audiencias, adaptar sus mensajes e involucrar a la población (U.S. Department of Health and Human Services, 2000; OMS, s.f.).

\section{La pandemia por el SARS-CoV-2}

El 31 de diciembre de 2019 el gobierno chino informó a la OMS sobre la existencia de un conglomerado de casos de neumonía en Wuhan, en la provincia de Hubei. El 11 de marzo dicha institución declaró la situación de pandemia causada por el coronavirus SARS-CoV-2. Para entonces el virus ya había alcanzado 114 países, infectado a 118.000 personas y provocado la muerte de 4.291. Se trataba de una crisis de salud pública y los países debían adoptar una estrategia basada en la participación de los gobiernos y la sociedad, enfocada a prevenir infecciones, salvar vidas y reducir al mínimo los efectos de la pandemia. Una de las recomendaciones de la OMS fue que se informara a la población de los riesgos existentes y la forma de protegerse de ellos (OMS, 2020; ONU, 2020; Valencia, 2020).

EI SARS-CoV-2 es un virus de la familia de los coronavirus cuyas siglas significan Síndrome Respiratorio Agudo Severo (Severe Acute Respiratory Syndrome en inglés) y la Covid-19 (coronavirus disease 2019 en inglés) es la enfermedad que éste provoca. Según distintos estudios los síntomas más comunes de la Covid-19 son: fiebre, tos, fatiga, dolor muscular y falta de aire al respirar, aunque pueden aparecer otros como náuseas, diarrea, dolor de cabeza, etc. Otros incluyen la pérdida de los sentidos del olfato y del gusto. También puede ocurrir que la persona contagiada de SARS-CoV-2 no desarrolle ningún síntoma y curse la enfermedad de forma asintomática. Se establecen la edad, el pertenecer al sexo masculino y padecer enfermedades cardiovasculares, respiratorias, diabetes, cáncer, obesidad e hipertensión como factores de riesgo de fallecer por Covid-19 (Sun, Lu, Xu, Sun \& Pan, 2020; Hadi, Kadhom, Hairunisa, Yousif \& Mohammed, 2020; Wang, Wang, Chen \& Qin, 2020; Yi, Lagniton, Ye, Li \& Xu, 2020; Jordan, Adab \& Cheng, 2020; Valencia, 2020; Wilder-Smith \& Freedman, 2020). Otro de los retos que plantea la enfermedad es que el propio sistema inmune puede agravar la patología y llegar a causar la muerte (García, 2020).

La transmisión del virus ocurre a través de gotículas respiratorias de personas infectadas 0 de contacto con superficies en las que esté presente. Los tiempos de incubación de la enfermedad según los primeros estudios disponibles varían entre 0 y 24 días (García, 2020; Valencia, 2020; Wilder-Smith \& Freedman, 2020).

Al no haber afectado nunca a humanos, la población global carece de inmunidad frente al SARS-CoV-2 (Yi et al., 2020). Además, no existe una vacuna ni un tratamiento específico que cure la enfermedad o evite la transmisión del virus. Por tanto, la única forma de impedir la transmisión comunitaria es el aislamiento de las personas que padecen Covid-19 y la cuarentena 0 la restricción de movimiento de los ciudadanos. Durante la cuarentena, aquellos que hayan estado en contacto con personas que han desarrollado la enfermedad o que puedan padecerla deben monitorizarse, y en caso de aparecer síntomas, aislarse (Kotwani \& Gandra, 2020; Wilder-Smith \& Freedman, 2020; Sun et al., 2020).

\section{La comunicación durante crisis sanitarias}

La comunicación de riesgos implica el intercambio en tiempo real de información, consejos y opiniones entre expertos, líderes comunitarios, funcionarios públicos y personas en situación de riesgo. Existen retos para que la comunicación de la salud sea efectiva, como diferencias sociodemográficas, culturales y económicas de la población, las cuales influyen en su percepción del riesgo y en la adopción de pautas de conducta que lo mitiguen (Georgiadis, 2013; OMS, 2018).

La incertidumbre que generan las crisis sanitarias hace necesario que los responsables en materia de salud generen confianza en la población. De lo contrario, aunque las intervenciones en comunicación de riesgos estén bien planificadas o ejecutadas, no llevarán a la población a tomar acciones que protejan su vida, su salud y las de sus familias y comunidades. Según la OMS, en situación de pandemia, la primera información oficial debe llegar en tiempo real, de forma simple y con el mayor alcance posible. Así mismo, debe actualizarse a medida que se recojan nuevos resultados o noticias. Según la Guía de comunicación en situaciones de brotes epidémicos de la 
OMS, deben tenerse en cuenta la confianza, el anuncio temprano, la transparencia en la recogida de datos, la evaluación de riesgos y toma de decisiones, el público y la planificación. Además, es importante incluir medios digitales e interactivos como las redes sociales, donde difundir información e interactuar con los ciudadanos (Urbina-Medina, Noguera Brizuela, Levy Mizhary, Carrizo, Betancourt, 2016; OMS, 2018).

Para que las instituciones sanitarias generen confianza en situaciones de crisis, deben tenerse en cuenta los siguientes aspectos: aportar información precisa y adecuada para evitar el fenómeno "infoxicación", destacar las fuentes oficiales de información, utilizar medios digitales para interactuar y sensibilizar a la población, reconocer la incertidumbre y enviar a la población mensajes sencillos con información segmentada por públicos y fiel a los hechos (UrbinaMedina et al., 2016; OMS, 2018).

La OMS establece los siguientes criterios para preparar mensajes claros y concisos durante situaciones de emergencia en salud pública: Identificar qué es lo más importante que queremos transmitir, qué necesitamos hacer para corregir informaciones y percepciones erróneas, comunicar nuestros puntos dominantes, preparar informaciones de apoyo para cada mensaje clave, desarrollar materiales que complementen a los mensajes (elementos visuales, ejemplos, historias personales, citas, analogías, instrucciones para obtener información adicional 0 respaldo de terceras partes fiables), mantener los mensajes cortos y simples y tener en cuenta a los individuos con mayores niveles de estrés 0 ansiedad y que requieren mensajes específicos. Estos pueden ser víctimas de la epidemia y sus familias 0 trabajadores sanitarios. En dichas audiencias hay que generar sentimientos de competencia, animar a crear sistemas de apoyo y canalizar respuestas negativas hacia acciones positivas.

Según la Guía para la Comunicación efectiva durante Emergencias de Salud Pública de la OMS (2005), a mayor nivel de estrés, miedo 0 ansiedad más simple debe ser el lenguaje. Hay que utilizar una gramática simple, frases cortas, ser cuidadoso al aportar cifras y evitar jerga, acrónimos y términos nuevos. En el caso de emplearlos, deben definirse para que la población los entienda. También es necesario utilizar materiales interactivos y presentar información compleja en niveles que aumenten su dificultad gradualmente. Son importantes la tipografía y el tamaño de fuente del texto, utilizando fuentes mayores en el caso de información para población con daños visuales 0 ancianos (WHO, 2005).
Resulta de gran utilidad la infografía, una combinación de textos e imágenes con alto valor comunicacional. Debe cumplir tres reglas en la comunicación institucional: cumplir el rigor informativo, cumplir el rigor científico y aumentar el nivel de conocimientos del receptor. Además, deben presentar equilibrio entre texto e imagen, ofrecer pequeñas cantidades de información en cada pieza, citar fuentes de información y no abusar de muchos colores. La información debe seguir el orden mental del público, de izquierda a derecha y de arriba a abajo, señalando el orden con flechas o números si es necesario (GonzálezPacanowski, 2009; OMS, 2020).

\section{La comunicación de la salud efectiva}

En situación de pandemia, una comunicación de riesgos eficaz hace que las personas en situación de riesgo entiendan y adopten medidas de protección. De igual forma, permite a autoridades y expertos escuchar y atender las preocupaciones y necesidades de la población para que los mensajes emitidos sean pertinentes, fidedignos y aceptables (OMS, 2018). Según U.S. Department of Health and Human Services (2000), deben unirse los medios de comunicación e Internet para incrementar la variedad de información y la extensión comunicativa. Al integrar en las campañas de salud pública elementos como Internet, videojuegos, televisión digital y teléfonos móviles, las audiencias alcanzadas son mayores y se expande la duración de la campaña. Gran parte de las herramientas que distribuyen información en Internet son gratuitas, haciendo la expansión de la campaña más fácil, eficiente y barata (de la Hera CondePumpido, 2009; Georgiadis, 2013).

Los medios interactivos presentan ventajas para la comunicación de la salud: 1) mejor acceso a información personalizada, 2) acceso a información, apoyo y servicios a demanda, 3) mejor capacidad de distribución extensa de materiales y de actualizar contenidos de forma rápida, 4) apoyo en la toma de decisiones de la mano de expertos en el momento y 5) más opciones para las audiencias. Pero también presentan desventajas, como la baja calidad de gran cantidad de información presente en Internet. La información sobre salud de alta calidad debe cumplir los siguientes requisitos: ser rigurosa, actual, válida, apropiada, inteligible e imparcial. Además, la comunicación de la salud ha de tener los siguientes atributos: exactitud, disponibilidad, imparcialidad, coherencia, competencia cultural, estar basada en la evidencia, tener alcance, fiabilidad, repetición, puntualidad y comprensibilidad. Es más efectiva si los mensajes se envían a través de múltiples canales y para 
segmentos de población específicos con información apropiada y relevante para ellos (U.S. Department of Health and Human Services, 2000; Georgiadis, 2013).

El éxito en las campañas de salud no solo depende de la calidad y la cantidad de los mensajes, también de la receptividad de las audiencias. Se debe informar sobre el tema de salud, sobre qué hay que hacer y cómo, y sobre por qué deben adoptarse esas medidas. Además, es necesario añadir credibilidad a través de mensajes atractivos, comprensibles y relevantes para el público. Con respecto a las redes sociales, pueden ser muy útiles a la hora de "promover la participación pública, facilitar la comunicación horizontal, mejorar el conocimiento de la situación, supervisar y rebatir rumores y atender las reacciones y preocupaciones de la población durante una emergencia, así como facilitar respuestas a nivel local" (Georgiadis, 2013; OMS, 2018; Costa-Sánchez \& LópezGarcía, 2020).

\section{Objetivo}

Analizar los materiales publicados en la página web del Ministerio de Sanidad, entre el 1 de marzo y el 18 de mayo de 2020, destinados a la población española como parte de la campaña Este virus lo paramos unidos, consecuencia de la pandemia por SARS-CoV-2.

\section{Metodología}

Se consultó el apartado "profesionales", subapartado "salud pública", donde se accedió a: Centro de Coordinación de Alertas y Emergencias Sanitarias (CCAES) (https://www.mscbs.gob.es/profesionales/ saludPublica/ccayes/home.htm); Alertas en Salud Pública de actualidad (https://www.mscbs.gob.es/profesionales/ saludPublica/ccayes/alertasActual/alertActu.htm) y por último Enfermedad por nuevo coronavirus, COVID-19 (https://www.mscbs.gob.es/profesionales/saludPublica/ ccayes/alertasActual/nCov/home.htm), seleccionando el apartado "Información para la ciudadanía".

\section{Criterios de inclusión}

Se analizaron todos los materiales sobre la pandemia por SARS-CoV-2 disponibles en castellano publicados en el apartado "Información para la ciudadanía" de la Web del Ministerio de Sanidad entre el 1 de marzo y el 18 de mayo de 2020. No se distinguió entre el tipo de material, siendo estos vídeos, infografías, carteles y documentos.

\section{Criterios de exclusión}

En el estudio no se incluyeron las infografías en otros idiomas (inglés, francés, árabe, chino y rumano). Se asumió que contenían la misma información que sus infografías homólogas en castellano. Así mismo, tampoco se incluyeron en los análisis vídeos de promoción de la campaña.

Tras consultar la bibliografía, se establecieron dos análisis para estudiar los materiales disponibles. En el primer análisis, de carácter cualitativo, se evaluaron los siguientes criterios: 1) exactitud en los mensajes en base a si están fundamentados científicamente, son gramaticalmente correctos, presentan faltas ortográficas y dan lugar a confusión; 2) claridad en el lenguaje atendiendo a si es sencillo, carente de jerga o terminología de difícil comprensión y, en el caso de infografías, presenta flechas o numeración que guíen los mensajes; 3) cantidad de texto; 4) presencia de fuentes de información; 5) posibilidad de establecer actualidad en función de si presenta fecha de publicación; y 6) presencia de apoyo visual.

El criterio 1 se estableció en base a OMS (2016), U.S. Department of Health and Human Services (2000) y Georgiadis (2013): presentar mensajes basados en la evidencia. En cuanto a las infografías, se tuvieron en cuenta las pautas establecidas por González-Pacanowski (2009). Con respecto al punto 2, se siguieron las indicaciones presentes en WHO (2005) y Urbina-Medina et al. (2016): no usar tecnicismos ni terminología técnica de difícil comprensión, atender a la tipografía y la fuente del texto y que los mensajes fueran sencillos y precisos. El criterio 3 se basa en WHO (2005) y OMS (2016): utilizar mensajes cortos, simples y concisos. El punto 4 se estableció en base a la Guía de comunicación de la OMS y Urbina-Medina et al. (2016): presentar fuentes oficiales. El quinto punto corresponde a lo establecido por la Guía de la comunicación de la WHO (2005) y por OMS (2018): aportar información en tiempo real. El punto 6 se establece en base a WHO (2005): incluir elementos y apoyo visuales.

En el segundo análisis, de carácter cuantitativo, se estudiaron los materiales en función del tipo de información que contenían: 1) el virus SARS-CoV-2 y/o la enfermedad Covid-19; 2) prevención de contagio por SARS-CoV-2; 3) promoción de la salud (alimentación, ejercicio físico, salud mental y hábitos saludables); 4) cuidados $y / 0$ recomendaciones para personas con síntomas de Covid-19; y 5) información destinada a grupos de riesgo.

El primer criterio de este segundo análisis se basa en las recomendaciones presentes en OMS (2016), Georgiadis (2013) y OMS (2018): hablar sobre el tema 
de salud, qué debe hacer la población y cómo. También se tuvieron en cuenta las normas de la OMS (2018) en los criterios 2 y 3 . El criterio 4 se rige por lo citado en U.S. Department of Health and Human Services (2000), Georgiadis (2013), Urbina-Medina (2016) y WHO (2005) y el quinto por lo mencionado en la Guía de comunicación de la OMS: segmentar la información por públicos y elaborar mensajes específicos para personas vulnerables.

\section{Resultados}

Al acceder a la web del Ministerio encontramos distintos apartados con cuatro tipos distintos de materiales: documentos, infografías, carteles y vídeos, que en su mayoría se agrupaban en un único apartado. Por ello, se analizó por un lado la sección "vídeos" y por otro las secciones que incluían otros materiales. Del total de materiales se excluyeron 2 vídeos que únicamente promocionaban la campaña y varias infografías redactadas en idiomas distintos del castellano. Los 90 materiales restantes se sometieron a un análisis cuantitativo y a otro cualitativo.

\section{Sección 1. Vídeos}

Añadimos una breve descripción y análisis de su contenido en base a lo expuesto en la metodología del presente estudio.

1.1 Aplanando la curva: Su mensaje clave es la disminución del número de personas infectadas por Covid-19 como consecuencia de las medidas de distanciamiento social. Incluye un gráfico que relaciona el número de casos nuevos con su fecha de aparición. Apela a la responsabilidad social con la frase "Así ayudarás a reducir la presión sobre el sistema sanitario y proteger a los más vulnerables". Intenta generar confianza en las autoridades sanitarias y mantener cierto comportamiento en la población.

1.2 Recomendaciones para personas mayores: Contiene información destinada a personas mayores, un grupo de riesgo frente a la Covid-19. Sus mensajes clave son: la prevención de contagio del virus mediante distanciamiento social, higiene de manos y uso de mascarilla; la prevención de accidentes domésticos y la promoción de la salud con consejos sobre higiene, alimentación, ejercicio físico y consumo de alcohol y tabaco. No incluye locución.

1.3 La importante labor de la atención primaria, también ante la covid-19: Su mensaje clave son las actividades que llevan a cabo los profesionales de atención primaria frente a la Covid-19, información que se apoya mediante una infografía. Utiliza terminología que la población podría no entender como: "Efectuar el control de los pacientes crónicos para que no se descompensen". Dos errores a destacar es que utiliza "el" para referirse a la enfermedad Covid-19 y en el título la "c" se escribe minúscula.

1.4 ¡Los niños ya pueden salir a pasear! Sigue la regla del 1: Al leer el título de este vídeo pensamos que su mensaje se destina a los niños, pero al abrirlo en YouTube encontramos como título: Deporte y paseos durante Covid-19. Esto puede generar confusión ya que, aunque incluye información específica de niños, también lo hace para otros grupos de población y para la práctica de deporte en la calle. Menciona medidas de prevención: lavado de manos, uso de mascarillas, mantenimiento de la distancia social y la necesidad de que las personas que presenten síntomas de Covid-19 se queden en casa. Incluye locución y utiliza animaciones como soporte visual de la información.

1.5 Si tienes síntomas: aíslate: Su mensaje clave es la prevención de contagios dentro del domicilio. Apela a la responsabilidad de las personas con la frase "Si te cuidas tú, cuidas a tu familia".

1.6 Un día más es un día menos: En este caso el vídeo promociona la campaña de salud y no es informativo, con lo cual no se incluyó en el análisis.

1.7 Nuevo coronavirus ¿qué es y cómo protegernos?: Su mensaje clave son los síntomas del nuevo coronavirus y las acciones preventivas a seguir para evitar su contagio. 1.8 ¿Para qué se están tomando medidas de control?: El mensaje clave es la repercusión que tienen en la evolución de la epidemia las medidas de control establecidas por las autoridades sanitarias. La información se completa con una gráfica que muestra el número de casos nuevos en el tiempo. Contiene expresiones que la población podría tener dificultad en comprender, por ejemplo "enlentecer el curso de la epidemia" o "saturación de los centros sanitarios". Incluye la fecha de publicación (10 de marzo) y las fuentes de información oficiales.

1.9 Estado de alarma ¿qué implica?: Su mensaje clave es la necesidad y la importancia de que las autoridades implementen medidas de control y prevención de expansión del virus y que la población civil las adopte en su vida diaria. Enumera los casos en los que se puede salir a la calle e informa sobre el cierre de lugares en los que no se puede mantener distancia social (restaurantes, centros deportivos, etc). Apela a la responsabilidad social con frases como "todos tenemos un papel para ayudar a parar este virus". También indica la fecha de publicación (20 de marzo).

1.10 Si tienes que salir de casa: El mensaje clave de este vídeo es la prevención de contagios por Covid-19. Contiene locución del texto y animaciones. 
1.11 Este virus lo paramos unidos: Se trata de un vídeo promocional de la campaña por lo que tampoco se incluye en el análisis.

1.12 ¿Qué es el covid 19?: El vídeo informa sobre el origen geográfico del virus y sus síntomas, pero no explica realmente qué es o cómo afecta al organismo. Su mensaje clave es la prevención. Por todo ello, su contenido resulta contradictorio con el título. Además, en el título menciona al virus como "el Covid-19" y la primera frase del texto comienza "El nuevo coronavirus COVID19...". Por ello, no utiliza un lenguaje riguroso. Contiene locución e insta a la población a informarse a través del Ministerio de Sanidad y de las autoridades sanitarias de las Comunidades Autónomas, por lo que busca generar confianza en la audiencia.

1.13 ¿Por qué aplanar la curva?: El mensaje clave de este vídeo es cómo las medidas de control y contención del virus pueden ayudar a reducir el número de personas contagiadas y mejorar la gestión de la epidemia. Fernando Simón, epidemiólogo y director del Centro de Coordinación de Alertas y Emergencias Sanitarias del Ministerio de Sanidad, habla a cámara y dibuja gráficas en una pizarra para explicar visualmente la información, aunque no indica qué representan sus ejes y por tanto la información exacta que éstas contienen. Utiliza lenguaje científico correcto según la bibliografía consultada, pero que puede resultar de difícil comprensión, ya que utiliza bastante jerga que la población general podría desconocer sin explicar lo que son, como "masa crítica de población", "transmisión diseminada", "número de reproducción", "caso primario", "caso secundario" o "transmisión comunitaria". En este caso, él mismo constituye una fuente de información experta.

1.14 Consejos para adolescentes: Su mensaje clave es la promoción de la salud a través de recomendaciones de ejercicio y uso responsable de las redes sociales. No incluye locución ni fecha de publicación. De nuevo llama a la responsabilidad individual con la frase "Tu papel es esencial".

1.15 Alergia y/o asma durante la epidemia covid-19. Recomendaciones: El primer mensaje es que las personas que padecen alergia no tienen mayor riesgo de contraer la infección por coronavirus, pero sí deben extremar las precauciones. El mensaje clave es la prevención de la infección por SARS-CoV-2. Utiliza pequeñas piezas de vídeo que acompañan a cada parte del texto. Su mayor error es que se inicia con la frase "Recomendaciones para personas con alergia y/o asma durante la epidemia de COVID-19" (en lugar de Covid-19), y no menciona el asma en ninguna parte del vídeo.
1.16 Bienestar emocional de niños y niñas. Covid-19: El mensaje clave es la promoción de la salud mental de los niños, aunque también incluye un apartado sobre prevención de la infección por SARS-CoV-2. Informa de los problemas que pueden tener los niños a la hora de comer y dormir, de emociones que pueden presentar, como enfado o tristeza, y de cómo manejarlo, así como la necesidad de enseñarles a seguir las medidas de higiene. Incluye fotos y clips de vídeo.

1.17 Limpieza en casa: Su mensaje clave es la prevención de contagios por Covid-19 en el domicilio. Incluye información sobre cómo limpiar superficies y ropa. Como fallo, en la última imagen con texto se solapa el logo del ministerio y la miniatura de otro vídeo, tapando así la información.

\section{Primer análisis de la sección "Vídeos"}

Criterio 1. Exactitud en los mensajes: Todos los vídeos excepto dos presentan una exactitud completa en la información que aportan basándonos en la bibliografía consultada. En ellos el error consiste en referirse al virus como "el Covid-19" en lugar de "SARS-CoV-2" o a la enfermedad Covid-19 como "COVID19".

Criterio 2. Claridad en el lenguaje: En todos los vídeos excepto uno el lenguaje es totalmente claro según los criterios establecidos en este estudio. Es gramaticalmente sencillo mediante el uso de frases cortas y evitando la jerga o terminología de difícil comprensión. El vídeo que presenta mayor dificultad contiene terminología utilizada en epidemiología. En el resto se destaca en color amarillo, rojo o negrita las frases o conceptos importantes. La tipografía, su tamaño y el contraste de color del texto con el fondo (blanco y negro) facilitan la lectura.

Criterio 3. Cantidad de texto: La mayoría de los vídeos tiene una duración inferior a un minuto y presenta el texto en piezas pequeñas que, por lo general, están formadas por una sola frase e incluso a veces una sola palabra, lo que facilita su lectura, comprensión y la retención de los mensajes.

Criterio 4. Presencia de las fuentes de información: Sólo se menciona al Ministerio de Sanidad como fuente de información. En muchos vídeos ni siquiera se cita al propio ministerio, y en el que aparece Fernando Simón no se le menciona como fuente experta, no se rotula su título ni cargo como autoridad sanitaria.

Criterio 5. Posibilidad de evaluar si la información estaba actualizada: Sólo 3 de los 15 vídeos analizados contenían la fecha de publicación, por lo que sólo en esos casos se podría establecer si la información estaba actualizada en ese momento. 
Criterio 6. Presencia de apoyo visual: En todos los vídeos se utiliza, ya sea en forma de gráficas, iconos, infografías, piezas de vídeo, fotografías, animación o recursos en el texto como resaltar las partes más importantes con un color diferente o negrita.

Segundo análisis de la sección "Vídeos"

De un total de 17 vídeos sólo dos contienen información general sobre el SARS-CoV-2 o la Covid-19, nueve hacen referencia a la prevención de infección por Covid-19, tres incluyen contenidos de promoción de la salud, tres informan sobre los cuidados o recomendaciones para personas enfermas de Covid-19 o que presentan algunos de sus síntomas, sólo uno se destina a grupos de riesgo frente a la enfermedad Covid-19 y dos son de promoción de la campaña. Para una visión más clara puede consultarse la tabla 1 más adelante.

En segundo lugar, se recogieron y analizaron los 75 materiales presentes en las siguientes secciones de la web: preguntas y respuestas, recomendaciones para cuidar la salud, bienestar emocional e higiene de manos. Éstos constituían 10 documentos, 60 infografías, 3 carteles y 2 vídeos. El formato más utilizado en los materiales analizados ha sido la infografía, seguida de vídeos, documentos y carteles.

Tabla 1. Segundo análisis de la sección 'Videos.

\begin{tabular}{|l|c|}
\hline \multicolumn{1}{|c|}{ Contenido } & Número de materiales \\
\hline $\begin{array}{l}\text { Información general sobre SARS-CoV-2 y } \\
\text { Covid-19 }\end{array}$ & 2 \\
\hline Prevención de contagios por Covid-19 & 3 \\
\hline Promoción de la salud & 3 \\
\hline $\begin{array}{l}\text { Cuidados y recomendaciones para } \\
\text { personas con síntomas }\end{array}$ & 1 \\
\hline $\begin{array}{l}\text { Destinados a grupos específicos de la } \\
\text { población }\end{array}$ & \\
\hline
\end{tabular}

Nota: Un mismo material puede contener más de un tipo de información. 


\section{Sección 2: Otros materiales}

Acontinuación, siguen cuatroapartados que analizaremos conjuntamente ya que se componen en su mayoría de infografías muy similares entre ellas.

\section{Subsección 2.1: Documentos}

2.1.1 Preguntas y Respuestas sobre el nuevo coronavirus (COVID-19): Este documento se divide en 11 apartados: ¿Qué es el nuevo coronavirus?, ¿Cuáles son los síntomas de COVID-19?, ¿Cuáles son los grupos vulnerables?, ¿Cómo se transmite el nuevo coronavirus?, ¿Cuál es la situación en España?, ¿Existe un tratamiento para el Covid-19?, ¿Qué puedo hacer para protegerme y proteger a los demás?, ¿qué medidas de control se están tomando?, ¿qué tengo que hacer si tengo síntomas?, ¿qué hago si conozco a alguien con síntomas de coronavirus? y Enlaces de interés. Ofrece información general sobre el virus, los grupos de riesgo, la enfermedad y la medicación que se da a las personas que la padecen, mencionando que no constituye una cura contra esta. Incluye los teléfonos de atención de cada comunidad autónoma, una infografía con recomendaciones sobre aislamiento domiciliario y otra sobre cómo actuar en caso de tener síntomas.

2.1.2 Aplanando la curva entre todos: El mensaje clave de este documento es mostrar la disminución de nuevos casos de Covid-19 en España como resultado de la aplicación del Estado de Alarma y las medidas de distanciamiento social. Contiene 6 epígrafes: Se está reduciendo el número de casos diarios, el ritmo de crecimiento diario de la epidemia está disminuyendo, ¿y esto qué significa?, ¿cuál es nuestra próxima meta?, ¿y qué tenemos que hacer para conseguirlo?, ¿y hasta cuándo?. Muestra la disminución del número de nuevos casos desde el 25 de marzo y la evolución de la epidemia. Incide en la necesidad de seguir adoptando las medidas establecidas por el gobierno, intentando crear así confianza y llamando a la responsabilidad ciudadana. También informa del número de personas a las que puede transmitir el virus una persona contagiada y expresa la necesidad de seguir las medidas de distanciamiento social para evitar rebrotes.

2.1.3 Guía de buenas prácticas en el centro de trabajo: Su mensaje clave es la prevención. Se divide en 8 epígrafes: Antes de ir al trabajo, desplazamientos al trabajo, en el centro de trabajo, medidas organizativas y recomendaciones a los trabajadores, medidas de higiene en el centro de trabajo, gestión de los residuos en los centros de trabajo y después del trabajo. Dentro de cada título enumera medidas a seguir para evitar contagios.

2.1.4 Guía de buenas prácticas en las salidas de la población infantil durante el estado de alarma: Transmite información, en un formato de pregunta y respuesta, sobre qué niños (menores de 14 años) y en qué condiciones pueden salir a la calle durante el estado de alarma. También incluye mensajes de prevención y recomendaciones de apoyo emocional y asistencia psicológica infantil.

2.1.5 Comunicación respecto a la información sobre los casos de shock pediátrico que circula en los medios de comunicación y redes sociales: Su función principal es transmitir calma a las familias.

\section{Primer análisis de la subsección "Documentos"}

Criterio 1. Exactitud en los mensajes: El primer documento, así como el segundo y el quinto informan de manera correcta y exacta. Sin embargo, en el primero, tercero y cuarto, aunque la mayoría del mensaje es correcto, se menciona al virus como "el Covid-19" o "COVID-19".

Criterio 2. Claridad en el lenguaje: El primer texto incluye conceptos complejos como "zoonótica", que son explicados a continuación para facilitar su comprensión. Mantiene un lenguaje claro y sencillo, al igual que el resto de documentos. Las dos guías utilizan numeración, guiones, viñetas y un formato pregunta-respuesta, facilitando su comprensión. Sin embargo, contienen términos que pueden resultar complejos y que no se explican: "caso primario", "vigilancia epidemiológica", "mascarilla higiénica" o "cubo de basura de fracción resto o indiferenciado".

Criterio 3. Cantidad de texto: En el primer, segundo y quinto documentos, de tres, dos y una página de longitud respectivamente, la cantidad de texto no es excesiva y los mensajes se separan por epígrafes que se dividen en párrafos de cuatro frases como máximo, facilitando su lectura. En el caso de las guías, tienen 13 y 10 páginas y contienen párrafos y frases más largas. No obstante, hacen uso del método pregunta-respuesta para agilizar su lectura.

Criterio 4. Presencia de las fuentes de información: En el primer documento encontramos diferentes fuentes de información: enlaces a distintas páginas de la web del Ministerio de Sanidad, un enlace a la web del Centro Europeo para la Prevención y el Control de 
Enfermedades y otro a la web de la OMS. En el segundo documento se menciona al Centro de Coordinación de Alertas y Emergencias Sanitarias y al Centro Nacional de Epidemiología del Instituto de Salud Carlos III de Madrid. La guía de buenas prácticas en los centros de trabajo sólo menciona al Ministerio de Sanidad, la guía de salidas de la población infantil cita a la OMS y el comunicado de shock pediátrico a la Asociación Española de Pediatría. Criterio 5. Posibilidad de evaluar si la información estaba actualizada: Todos los materiales tienen fecha de publicación. Además, en "Preguntas y respuestas sobre COVID-19" vemos indicaciones de que los mensajes están actualizados ya que enumera más síntomas que en los vídeos y añade un enlace que indica la situación de España en el momento de la consulta.

Criterio 6. Presencia de apoyo visual: En "Aplanando la curva entre todos" encontramos tres gráficas. En las guías hay ilustraciones que no apoyan al texto, excepto una enfocada a la distancia entre personas. No se utilizan infografías ni iconos en ninguno de los documentos.

\section{Segundo análisis de la subsección "Documentos"}

De estos materiales, uno contiene información general sobre el virus y la enfermedad, tres contienen mensajes sobre prevención, ninguno trata la promoción de la salud, tres contienen recomendaciones o cuidados para personas con síntomas de Covid-19 y uno está destinado a grupos específicos de la población, en este caso los menores de 14 años.

Subsección 2.2: Documentos, Infografías, carteles y vídeos

2.2 Preguntas generales: Consta de 13 materiales, 10 infografías y 3 carteles: ¿Qué es el nuevo coronavirus SARS-CoV-2?, ¿Como se transmite?, ¿Cuáles son los síntomas del nuevo coronavirus?, ¿Existe tratamiento para el nuevo coronavirus?, ¿Qué puedo hacer para protegerme del nuevo coronavirus y otros virus respiratorios?, Nuevo coronavirus. Qué hacer, Decálogo sobre cómo actuar en caso de tener síntomas de Covid-19, No subestimes el aislamiento, Recomendaciones para el aislamiento domiciliario en casos leves de Covid-19, ¿Qué hago si conozco a alguien con síntomas de coronavirus?, ¿Cómo se diagnostica el Covid-19 a personas con síntomas?, ¿Has estado en contacto con alguien con síntomas de Covid-19? ¿Qué les digo a niños y niñas sobre el coronavirus? Analizaremos estos materiales junto con los pertenecientes a las siguientes secciones.

2.2.1 Consejos para el día a día: Consta de 16 materiales: 13 infografías y 3 documentos: Franjas horarias, salidas, paseos y deporte, Redes comunitarias en las crisis de Covid-19, Salidas de la población infantil, Uso mascarilla higiénica, Uso mascarilla quirúrgica, Limpieza general de la vivienda, ¿Qué hacer con la limpieza de superficies?, Al llegar a casa; Como hacer las compras de primera necesidad, Cómo hacer las compras imprescindibles en la farmacia, Compartir mensajes en redes, Cómo usar correctamente la mascarilla, Los virus no discriminan, las personas tampoco deberíamos hacerlo, Derechos de consumidores y usuarios ante la situación provocada por el coronavirus (Covid-19), ¿Qué debes tener en cuenta al comprar una mascarilla? y ¿Debes usar guantes al salir de casa?

2.2.2 Recomendaciones para cuidar la salud: Diez materiales conforman esta sección: 9 infografías y 1 documento: Recomendaciones actividad física, Recomendaciones alimentación, Recomendaciones consumo de tabaco, Recomendaciones consumo alcohol, Recomendaciones para personas mayores, Recomendaciones para cuidadores y familiares de mayores y personas vulnerables, Vacunación durante el estado de alarma, Seguridad en personas mayores para evitar accidentes en el hogar, Seguridad en niños y niñas frente a accidentes en el hogar y por último, Información y pautas generales para mujeres embarazadas en situación de confinamiento.

2.2.3 Recomendaciones para personas con condiciones de salud crónicas: Contiene 16 materiales formados por 15 infografías y un documento: Guía de actuación para personas con condiciones de salud crónicas y personas mayores en situación de confinamiento, Recomendaciones para niños y niñas con trastorno del espectro autista, Recomendaciones para personas con epilepsia, Atención sanitaria a personas con condiciones de salud crónicas en atención primaria, Recomendaciones para personas con Enfermedad Pulmonar Obstructiva Crónica, Recomendaciones para personas con alergia/asma, Recomendaciones para pacientes anticoagulados, Servicios sociales de atención domiciliaria, Recomendaciones para personas con cáncer, Recomendaciones para personas con diabetes, Recomendaciones sobre la medicación para personas con condiciones de salud crónicas, Recomendaciones 
para pacientes con enfermedad renal crónica en diálisis, Infarto agudo de miocardio, Recomendaciones para personas con fibrosis quística, Ictus y Recomendaciones para personas con hipertensión arterial, todo ello adaptado a la pandemia por Covid-19.

2.2.4 Bienestar emocional: Lo forman ocho infografías: Impacto emocional por Covid-19, Recomendaciones de apoyo emocional para niños y niñas durante la epidemia de Covid-19, Consejos para sobrellevar mejor el quedarte en casa, Consejos para adolescentes en casa, Afrontar el duelo en tiempos de coronavirus, Acompañar en el duelo, Acompañar a niños y niñas en el duelo y Teléfonos de asistencia psicológica.

\subsubsection{Higiene de manos}

\section{-Población general}

Contiene un vídeo y tres infografías con los siguientes títulos: ¿Cuándo debo lavarme las manos?, Lavarse las manos: por qué y cuándo, lavarse las manos y ¿Cómo debo lavarme las manos?.

-Población infantil

Está conformado por dos infografías y un vídeo: ¡Así me lavo bien las manos! (título del vídeo y de una de las infografías) y ¡Lávate las manos! El vídeo muestra a una persona lavándose las manos con agua y jabón mientras un texto y una locución explican cómo lo hace.

Primer análisis de la subsección "Documentos, Infografías, carteles y vídeos"

Criterio 1. Exactitud en los mensajes: La información es correcta y más detallada y completa que en los vídeos: incluye más síntomas y datos específicos para grupos de riesgo. Sin embargo, se menciona al virus como SARSCOV2 y a la enfermedad como COVID-19, excepto en la infografía "los virus no discriminan, las personas tampoco deberíamos hacerlo", en la dedicada a la vacunación y en la que trata el bienestar emocional en adolescentes.

Criterio 2. Claridad en el lenguaje: Aparecen de forma esporádica términos que podrían no ser claros: "ARN", "patógeno", "monitorice" o "germen", pero por lo general se utiliza lenguaje sencillo y sin jerga. En el documento destinado a embarazadas aparecen términos complejos como "puerperio" y "transmisión vertical", aunque esta última se explica. Se resalta información importante con colores o negrita, la tipografía, el contraste entre texto y fondo y la agrupación de texto en secciones con colores distintos según la información contenida.
Criterio 3. Cantidad de texto: Es variable, sobre todo entre infografías. La más concisa comprende una página con tres frases cortas. Otras infografías tienen 2 páginas de varios párrafos cada una. Las más extensas se dividen en apartados con colores diferentes, lo que atrae la atención del lector y separa los mensajes por secciones, haciendo más fácil la comprensión y retención de información.

Criterio 4. Presencia de las fuentes de información: En todos los materiales se indica la necesidad de informarse en fuentes oficiales, pero la mayoría sólo incluye al Ministerio de Sanidad. En la infografía sobre aislamiento domiciliario se menciona al Ministerio de Sanidad de Reino Unido y a la Consejería de Sanidad de Asturias. En la infografía destinada a mujeres embarazadas y en la guía de actuación se menciona a la OMS. En la guía y en la infografía dedicadas a las personas con cáncer, se incluye el teléfono de la Asociación Española Contra el Cáncer para ampliar información. La infografía sobre el Trastorno del Espectro Autista incluye la web de la ONG Autismo.org. Muchas de las infografías incluyen enlaces a otras para ampliar información sobre un tema concreto. Criterio 5. Posibilidad de evaluar si la información está actualizada: Todos los materiales indican su fecha de publicación por lo que puede valorarse si contienen información actual. Además, aparecen otros indicadores como fechas o expresiones tal que "según las últimas investigaciones".

Criterio 6. Presencia de apoyo visual: La práctica totalidad de los materiales se apoya en recursos visuales, incluyendo los documentos. Además de los recursos mencionados en el punto tres se utilizan iconos, dibujos, flechas, numeración, gráficas, fotografías y vídeo.

Segundo análisis de la subsección "Documentos, Infografías, carteles y vídeos"

En base al segundo análisis de los materiales de esta sección un total de 10 contienen información general sobre el virus y/o la enfermedad, 36 sobre prevención de contagios, 23 sobre promoción de la salud, 17 sobre cuidados y/o recomendaciones para personas que padecen síntomas de Covid-19 y 18 están destinados a grupos específicos de la población. Los resultados de esta sección se reflejan a continuación en la tabla 2 . Como se especifica en las notas de la misma, un mismo documento o infografía puede presentar más de un tipo de contenido informativo, por ejemplo datos sobre el virus y también cuidados y recomendaciones. 
Tabla 2. Segundo análisis de la sección "Otros materiales".

\begin{tabular}{|l|c|c|c|}
\hline \multicolumn{1}{|c|}{ Contenido } & Sección 2.1 & Sección 2.2 & Total \\
\hline $\begin{array}{l}\text { Información } \\
\text { general }\end{array}$ & 1 & 10 & 11 \\
\hline $\begin{array}{l}\text { Prevención de } \\
\text { contagios }\end{array}$ & 3 & 36 & 39 \\
\hline $\begin{array}{l}\text { Promoción de la } \\
\text { salud }\end{array}$ & 0 & 23 & 23 \\
\hline $\begin{array}{l}\text { Cuidados y } \\
\text { recomendaciones }\end{array}$ & 3 & 17 & 20 \\
\hline $\begin{array}{l}\text { Destinados a } \\
\text { grupos específicos }\end{array}$ & 1 & 18 & 19 \\
\hline
\end{tabular}

Nota: Un mismo material puede contener más de un tipo de información.

\section{Discusión}

En la sección "Vídeos" casi todos, 14 de los 15 analizados, contienen información exacta y rigurosa, en 14 de ellos se utiliza un lenguaje claro, carente de jerga. La cantidad de texto o locución es pequeña en la mayoría de ellos, facilitando la transmisión del mensaje. En cuanto a la presencia de fuentes de información es necesario apuntar que sólo se indica al propio Ministerio de Sanidad. Según las recomendaciones estudiadas, esto genera confianza en el propio Ministerio. Sin embargo, es recomendable utilizar otras fuentes de información científica como los Centros para el Control y la Prevención de Enfermedades o la OMS. Por otro lado, 12 de los 15 vídeos no incluyen fecha de publicación, por lo que no se pudo establecer si la información estaba actualizada en ese momento. Por último, todos incluyeron apoyo visual en distintos formatos como iconos, gráficas o infografías. Es importante resaltar que muchos de ellos no incluyen locución. Por ello, personas con dificultades auditivas, como las personas mayores, que además son población de riesgo por complicaciones frente a la Covid-19, podrían no tener acceso a la información.

En cuanto al análisis cualitativo, que puede consultarse en la Tabla 1, el contenido que mayor presencia tiene, con un total de 9 videos, es la prevención de contagios por Covid-19. A continuación, la promoción de la salud y cuidados y recomendaciones para personas con síntomas de Covid-19, con tres vídeos cada uno, dos para grupos específicos de población y únicamente un vídeo con información general del virus y la enfermedad.
Respecto al resto de secciones analizadas (preguntas y respuestas, recomendaciones para cuidar la salud, bienestar emocional e higiene de manos), la mayoría de los materiales presenta información correcta y rigurosa si se compara con los estudios consultados sobre el SARS-CoV-2 y la Covid-19. Por lo general, sobre todo en el caso de los documentos, se proporciona más información y más detallada que en la sección "Vídeos". Sin embargo, se cometen errores importantes en algunos documentos e infografías como "el Covid-19", "SARS-COV2 o "COVID-19". En cuanto a la claridad en el mensaje, la tipografía, la fuente de los textos o el color de fondo en el caso de carteles e infografías hacen los mensajes fáciles de entender. Además, la gran mayoría de los mensajes son claros, aunque algunos utilizan terminología y jerga que la población podría no comprender. La cantidad de texto varía mucho entre carteles o infografías en comparación con los documentos, especialmente las guías, que tienen varias páginas. En los documentos la información se separa por párrafos y epígrafes que facilitan la lectura.

En cuanto a la presencia de fuentes de información, igual que en la sección anterior, la mayoría de materiales menciona únicamente al Ministerio de Sanidad. Sólo en algunos documentos se citan las siguientes fuentes: la OMS, el Centro Europeo para la Prevención y el Control de Enfermedades, el Centro de Coordinación de Alertas y Emergencias Sanitarias, el Centro Nacional de Epidemiología del Instituto de Salud Carlos III de Madrid, la Asociación Española de Pediatría, el Ministerio de Sanidad de Reino Unido, la Consejería de Sanidad de 
Asturias, la Asociación Española Contra el Cáncer y la ONG Autismo.org. Esto podría interpretarse como una falta de transparencia por parte del Ministerio ya que no aporta otras fuentes con las que contrastar la información.

Por otro lado, la mayoría de los materiales presentan fecha de publicación, por lo que en el momento era posible establecer si la información estaba actualizada. Por último, la mayoría de materiales incluye apoyo visual, como gráficas, flechas o iconos.

En cuanto al segundo análisis de la sección "Otros materiales", los resultados, que pueden consultarse en la Tabla 2, muestran que la mayoría de materiales, 39 de ellos, contiene información sobre la prevención de contagios por Covid-19, seguido de 23 materiales con información destinada a la promoción de la salud, 20 con referencias a cuidados y/o recomendaciones para personas que presenten síntomas, 19 con información enfocada a grupos específicos de la población y, por último, 11 con información general sobre el virus SARSCoV-2 y/o la enfermedad Covid-19.

Los resultados generales del análisis cualitativo son positivos, sobre todo en cuanto a la claridad del mensaje, la presencia de fechas de publicación y la presencia de apoyo visual. Como aspectos a mejorar destacan la presencia de otras fuentes de información que no sean el propio ministerio, la adaptación de los materiales para personas con dificultades visuales y errores graves, pero puntuales, como escribir de forma incorrecta el nombre del virus o la enfermedad que provoca.

En cuanto al análisis cuantitativo global, los materiales se enfocan en la prevención de contagios por Covid-19, como indica la OMS. No obstante, deberían haberse elaborado más materiales sobre el virus y la enfermedad, ampliando la información sobre sus síntomas o los factores de riesgo para desarrollar complicaciones por SARS-CoV-2.

No se ha considerado a personas con problemas visuales, ya que la mayoría de los materiales escritos no tenía un homólogo en audio y casi la totalidad de los videos no incluye locución. Además, habría sido recomendable crear materiales que desmintieran los bulos y desinformación presentes en redes sociales (Costa-Sánchez \& López-García, 2020).

Como limitaciones cabe destacar que los estudios sobre el virus y la enfermedad con que se contrastaron los materiales analizados podrían ir quedando desactualizados a lo largo del estudio y que apenas se encontraron análisis de comunicación de la salud sobre la actual pandemia, ya que aún se desconocían muchos aspectos de la misma. Además, no se analizaron otras comunicaciones del Ministerio de Sanidad como ruedas de prensa, notas de prensa o contenido de sus redes sociales. Sería recomendable incluir información de las webs, redes sociales y aplicaciones para smartphone del Ministerio de Sanidad y de las autoridades sanitarias de cada Comunidad Autónoma para tener una visión completa de la campaña (Villegas-Tripiana, Villalba-Díaz, \& López-Villegas, 2020). Futuras líneas de investigación deberían tener en cuenta otros materiales no incluidos en este análisis y estudiar el efecto de la campaña a través de encuestas a la población general.

\section{Conclusiones}

La comunicación de la salud por parte del Ministerio de Sanidad a través de los materiales analizados en el presente estudio ha sido en general positiva en cuanto al tipo de información que contienen, la exactitud, claridad y longitud en los mensajes, así como la presencia de fechas de publicación, con algunos aspectos a mejorar como la presencia de otras fuentes de información y la adaptación de los mismos a personas con dificultades visuales.

\section{Financiación}

Esta investigación no recibió financiación.

\section{Declaración de disponibilidad de datos}

Los datos presentados en este estudio pueden ser solicitados al autor de correspondencia.

\section{Agradecimientos}

A todos aquellos que participaron en la revisión del presente estudio.

Conflicto de interés

El autor declara que no hay conflicto de interés.

\section{Referencias bibliográficas}

Costa-Sánchez, C., \& López-García, X. (2020). Comunicación y crisis del coronavirus. Primeras lecciones. El profesional de la información, 29(3). https://doi.org/10.3145/epi.2020.may.04

de la Hera Conde-Pumpido, T. (2009). Comunicación Institucional Online: Un modelo para el análisis de usos y potencialidades de la web 2.0. El caso de la Gripe A. Actas del I Congreso Internacional Latina de Comunicación Social, 2009. Tenerife: Universidad de la Laguna. Recuperado de: http://hdl. handle.net/1765/110505 
U.S. Department of Health and Human Services. (2000). Healthy People 2010. U.S. Government Printing Office.

García, L.F. (2020). Immune Response, Inflammation, and the Clinical Spectrum of COVID-19. Frontiers in Immunology, 11, 1441. https://doi.org/10.3389/ fimmu.2020.01441

Georgiadis, M. (2013). Motivating Behavior Change: A Content Analysis of Public Service Announcements From the Let's Move! Campaign. Elon Journal of Undergraduate Research in Communications, 4(1), 2-3.

González-Pacanowski, T., \& Medina, P. (2009). Comunicación online en el sector salud. El valor de la infografía. El Profesional de la Información, 18(4), 413-420.

Hadi, AG., Kadhom, M., Hairunisa, N.,Yousif, E., \& Mohammed, SA. (2020). A review on COVID-19: Origin, Spread, Symptoms, Treatment and Prevention. Biointerface Research in Applied Chemistry, 10(6), 7234-7242. https://doi. org/1033263/BRIAC106.72347242

Jordan, R.E., Adab, P., \& Cheng, K.K. (2020). Covid-19: risk factors for severe disease and death. British Medical Journal, 368, m1198. https://doi. org/10.1136/bmj.m1198

Kotwani, A., \& Gandra, S. (2020). Potential pharmacological agents for COVID-19. Indian Journal of Public Health, 64(6), 112-116. DOI: 10.4103/ijph.IJPH_456_20

Organización Mundial de la Salud. (s.f). ¿Cómo define la OMS la salud?. Consultado el día 27 de abril de 2020 de la World Wide Web: https://www.who.int/es/ about/who-we-are/frequently-asked-questions

Organización Mundial de la Salud. (2016, agosto). ¿Qué es la promoción de la salud?. Recuperado de: https://www.who.int/features/qa/health-promotion/es/

Organización Mundial de la Salud. (2018). Comunicación de riesgos en emergencias de salud pública. Directrices de la OMS sobre políticas y prácticas para la comunicación de riesgos en emergencias (CRE). Recuperado de: https://apps.who.int/iris/ bitstream/handle/10665/272852/9789243550206spa. pdf?sequence $=1$ \&isAllowed $=y$
Organización Mundial de la Salud. (11 de marzo de 2020). Alocución de apertura del Director General de la OMS en la rueda de prensa sobre la Covid-19 celebrada el 11 de marzo de 2020. Recuperado de: https://www.who.int/es/dg/speeches/detail/whodirector-general-s-opening-remarks-at-the-mediabriefing-on-covid-19---11-march-2020

Organización delas Naciones Unidas. (15deabril de 2020). Cronología de la pandemia del coronavirus y actuación de la Organización Mundial de la Salud. Recuperado de: https://news.un.org/es/story/2020/04/1472862

Sun, P., Lu, X., Xu, C., Sun, W., \& Pan, B. (2020). Understanding of COVID-19 based on current evidence. Journal of Medical Virology, 92(6), 548-551. https://doi.org/10.1002/jmv.25722

Urbina-Medina, H., Noguera Brizuela, D., Levy Mizhary, J., Carrizo, J., \& Betancourt, A. (2016). Comunicación efectiva y ética en casos de epidemias y pandemias. Archivos Venezolanos de Puericultura $y$ Pediatría, 79(4), 113-117.

Valencia, D. N. (2020). Brief Review on COVID-19: The 2020 Pandemic Caused by SARS-CoV-2. Cureus, 12(3), e7386. https://doi.org/10.7759/cureus.7386

Villegas-Tripiana, I., Villalba-Díaz, A. \& Lopez-Villegas, A. (2020). Análisis de la información sobre COVID-19 en sitios web de organizaciones sanitarias. Revista Española de Comunicación en Salud, S1, S234242. https://doi.org/10.20318/recs.2020.5437

Wang, Y., Wang, Y., Chen, Y., \& Qin, Q. (2020). Unique epidemiological and clinical features of the emerging 2019 novel coronavirus pneumonia (COVID-19) implicate special control measures. Journal of Medical Virology, 92(6), 568-576. https://doi. org/10.1002/jmv.25748

Wilder-Smith, A. \& Freedman, D. O. (2020). Isolation, quarantine, social distancing and community containment: pivotal role for old-style public health measures in the novel coronavirus (2019-nCoV) outbreak. Journal of Travel Medicine, 27(2), taaa020. https://doi.org/10.1093/jtm/taaa020

World Health Organization. (2005). WHO Outbreak Communicationguidelines. Recuperadode:https:// apps.who.int/iris/bitstream/handle/10665/69369/ WHO_CDS_2005_28_eng.pdf?sequence=1 
World Health Organization. (2005). Effective Media Communication during Public Health Emergencies. A WHO Field Guide. Recuperado de: https://www.who.int/csr/resources/publications/ WHO_CDS_2005_31/en/

Yi, Y., Lagniton, P., Ye, S., Li, E. \& Xu, R. H. (2020). COVID-19: what has been learned and to be learned about the novel coronavirus disease. International Journal of Biological Sciences, 16(10), 17531766. https://doi.org/10.7150/ijbs. 45134 